\title{
Neoichnology of Thyonella gemmata: A Case Study for Understanding Holothurian Ichnofossils
}

\author{
Krista R. Smilek ${ }^{1,2}$ and Daniel I. Hembree ${ }^{* 2}$ \\ ${ }^{1}$ Department of Geology, University of Cincinnati, Cincinnati, OH 45221, USA \\ ${ }^{2}$ Department of Geological Sciences, Ohio University, 316 Clippinger Laboratories, Athens, OH, 45701, USA
}

\begin{abstract}
While the fossil record of holothurians extends from the Cambrian to the Holocene, adequately evaluating their temporal and spatial distribution is difficult due to their poor preservation potential. Several extant holothurians, however, produce abundant shallow burrows that a have a high preservation potential. Neoichnological experiments allow for the direct observation of burrowing behaviors and the resulting biogenic structures. Data obtained from these experiments are invaluable to the interpretation of ichnofossils lacking associated body fossils. The burrowing behaviors of the holothurian Thyonella gemmata were studied in a laboratory setting under varying environmental conditions. Specimens were exposed to variations in grain size, salinity, and water temperature to assess their behavioral response to environmental change and any resulting biogenic structures. Thyonella gemmata burrows by intruding itself into the sediment using muscular contractions and limited use of tube feet. Thyonella gemmata contracts its body into a U-shape and maintains contact with the sediment surface. The resulting burrow is a wide, U-shaped concentration of disrupted sediment with or without spreite. Sediment size had the greatest effect on burrowing activity and morphology; individuals were able to easily burrow into fine- and medium-grained sand, but experienced difficulty in coarse-grained sand. Altering water temperature yielded no significant results. While increasing salinity had no effect, lowering salinity had an adverse physiological effect on the specimens and inhibited burrowing. Studying the varying burrow morphologies produced in these experiments will aid in the interpretation of potential holothurian ichnofossils and the interpretation of paleoenvironmental conditions.
\end{abstract}

Keywords: Burrowing, trace fossil, echinoderm, marine, ichnology.

\section{INTRODUCTION}

The purpose of this study is to document the burrowing behavior and biogenic structures of the extant holothurian, Thyonella gemmata (Dendrochirotida: Cucumariidae) (Fig. 1) for the purpose of identifying holothurian-produced ichnofossils in the rock record. In addition to studying basic burrowing behaviors and burrow morphology, the experiments involved exposing $T$. gemmata to altering environmental parameters in order to trigger changes in burrowing behavior, which would likely be recorded in the burrow morphology. Holothurians, commonly referred to as sea cucumbers, are vagile, soft-bodied members of the phylum Echinodermata [1,2]. Locomotion along the sea floor is facilitated by the use of podia, or tube feet, which are driven by a water vascular system [1]. The dorsal surface generally contains two ambulacral areas with reduced podia while the ventral surface contains three ambulacral areas with longer podia directly involved in locomotion [1]. The podia around the mouth are modified into tentacles for feeding (Fig. 1B) [2]. Holothurians have well-developed longitudinal muscles in their body wall, which are used to assist locomotion across the surface as well as in burrowing [2]. Thousands of microscopic calcareous sclerites, ranging in size from 0.05 to $2.0 \mathrm{~mm}$ and occurring in a variety of shapes, reinforce the

*Address correspondence to this author at the 316 Clippinger Laboratories, Department of Geological Sciences, Ohio University, USA; Tel: 740-5971495; Fax: 740-593-0486; E-mail: Hembree@ohio.edu
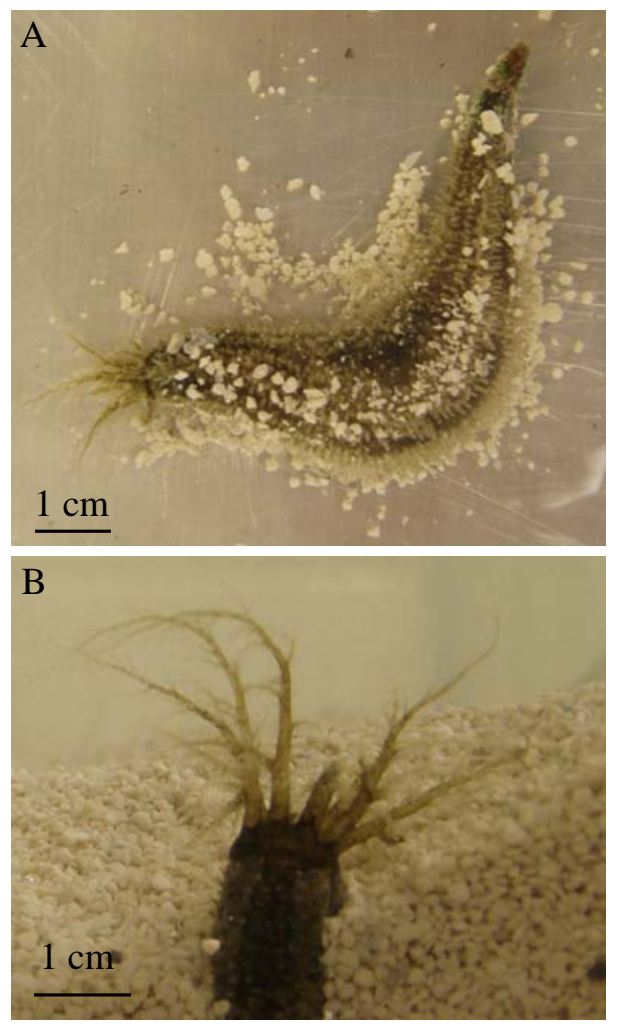

Fig. (1). A) Full view of a specimen of T. gemmata with extended tentacles and podia projecting from the body. B) Burrowed specimen with tentacles extending during suspension feeding. 


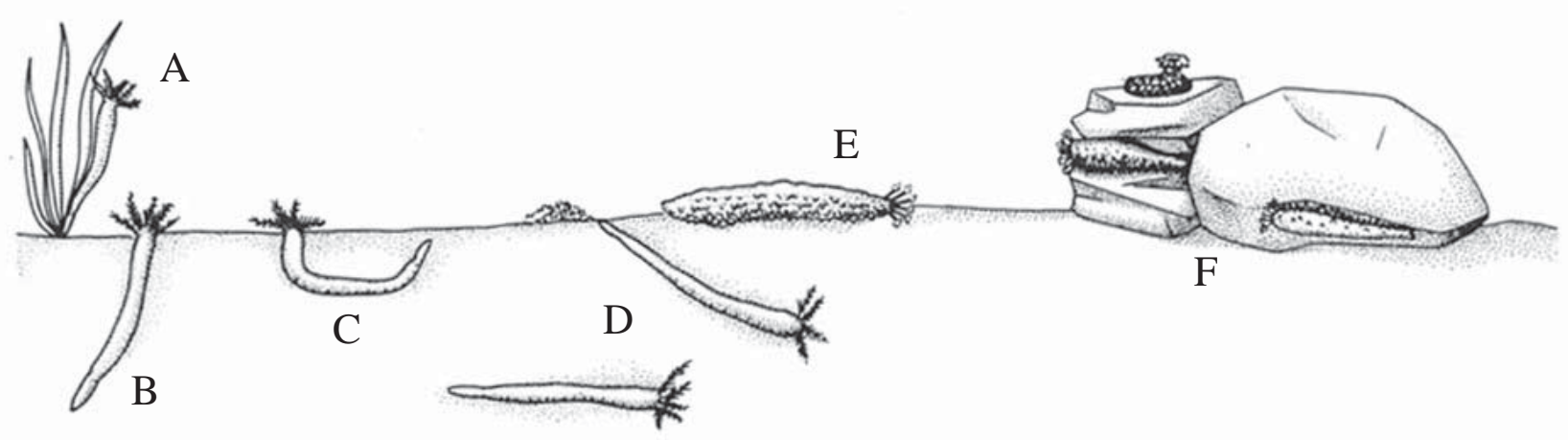

Fig. (2). The various environmental niches occupied by holothurians on and within the sea floor. A) Attached to marine plants. B-D) Burrowed into soft sediment. E) Lying on sediment. F) Hidden in rock crevices and coral heads. Modified from [2].

body wall [3]. When disturbed, holothurians contract the muscles in their body wall causing the sclerites to overlap. The overlapping sclerites toughen the outer body wall and aid in protecting the holothurian from predation [2].

Holothurians inhabit marine environments from the equator to the poles and occur in a range of waters depths from shallow tropical waters to deep-water troughs $[1,2,4$, 5]. Holothurians have a low tolerance for salinity change and are strictly marine organisms [3]. Holothurians are found on sandy, muddy, or rocky substrates and may attach themselves to marine plants, such as sea grass (Fig. 2A), burrow into the substrate (Fig. 2B, C, D), roam along the sea floor (Fig. 2E), or hide within the crevices in coral heads or underneath rocks (Fig. 2F) [2]. Many species produce permanent burrows in the sediment [6]. Burrowing species often keep their anterior and posterior ends in contact with the sediment-water interface (Fig. $\mathbf{2 B}, \mathbf{C}$ ) in order to maintain a ventilating current through the burrow [2]. There are both deposit- and suspension-feeding holothurians; while the burrowing species are generally suspension-feeders, they are also capable of deposit-feeding with their tentacles [2].

Holothurians have a very sparse body fossil record due to the poor preservation potential of their predominately soft anatomy [7]. While their fossil record extends to the Middle Cambrian, whole fossil specimens are rare and most occurrences consist of isolated sclerites [7]. Since the preservation potential of complete holothurians is very poor, ichnology can be employed to better evaluate the distribution of holothurians in the fossil record. Trace fossils are biogenic sedimentary structures that are preserved in situ, unlike body fossils that can be transported or altered during and after fossilization $[8,9]$. Trace fossils are interpreted as the result of the behaviors of epi- or infaunal organisms as they moved on or through ancient sediments in response to their environment $[8,9]$. In order to better interpret trace fossils, neoichnological experiments are performed with modern organisms in the field and laboratory to observe burrowing activities and resulting trace morphologies [9]. These burrow morphologies can then be compared to trace fossils to determine possible tracemakers and behaviors.

\section{MATERIALS AND METHODS}

Thyonella gemmata was chosen for this neoichnological experiment of holothurians because they are well-docu- mented burrowers that occur in large numbers in nearshore environments. Thyonella gemmata are also resilient animals and are well-suited for laboratory study. Despite these facts, the burrowing behavior of $T$. gemmata has not been extensively studied. Previous studies of these organisms have focused on the physiology of T. gemmata [10], but there have been no documented ichnological studies.

Thyonella gemmata is a small holothurian, measuring approximately $8 \mathrm{~cm}$ in length when at rest. The body of the holothurian narrows at each end, widens toward the middle, and is grayish brown in color (Fig. 3). When disturbed, $T$. gemmata, like other holothurians, contracts its body and becomes rigid for protection $[1,5]$. Thyonella gemmata commonly inhabits nearshore sandy and muddy sediment in subtropical shallow marine environments [1]. The specimens for this experiment were acquired from the shallow waters of the northern Gulf of Mexico along the Florida coast. This is a dynamic environment affected by daily and seasonal temperature fluctuations and storms as well as tidal activity. Thyonella gemmata are typically burrowed beneath the sediment surface, but they do maintain contact with the sediment surface in order to extend the tentacles from the anterior portion of the body to filter feed and the posterior end to expel wastes (Fig. 3B) [1]. This contact also maintains water circulation through the burrow for respiration $[1,4,5]$.

Four Thyonella specimens were observed in a laboratory setting. The specimens were housed in three $76.5 \mathrm{~cm} \times 45$ $\mathrm{cm} \times 63 \mathrm{~cm}(\mathrm{~L} \times \mathrm{W} \times \mathrm{H}), 212 \mathrm{~L}$ aquaria. Tank 1 housed one specimen kept under constant environmental conditions, which served as the control. Tanks 2 and 3 housed one and two specimens respectively. Two specimens were placed in a single tank in order to observe interactions between individuals. The substrate, salinity, and temperature were initially uniform in each of the tanks (Table 1A). The substrate consisted of pink aragonite sand with a grain size of $0.5-1.5 \mathrm{~mm}$. The aragonite sand was mixed with "live sand" with approximately the same grain size range that also contained various marine bacteria. The salinity of the tanks was maintained between $29.2-31.9 \%$, which is equivalent to a specific gravity range between $1.022-1.024$. The water temperature in the tanks was kept between $20-22^{\circ} \mathrm{C}$. Each of the tanks was tested regularly to insure that proper $\mathrm{pH}$, nitrate, nitrite, and ammonia levels were within a suitable range. The specimens were given approximately one month 

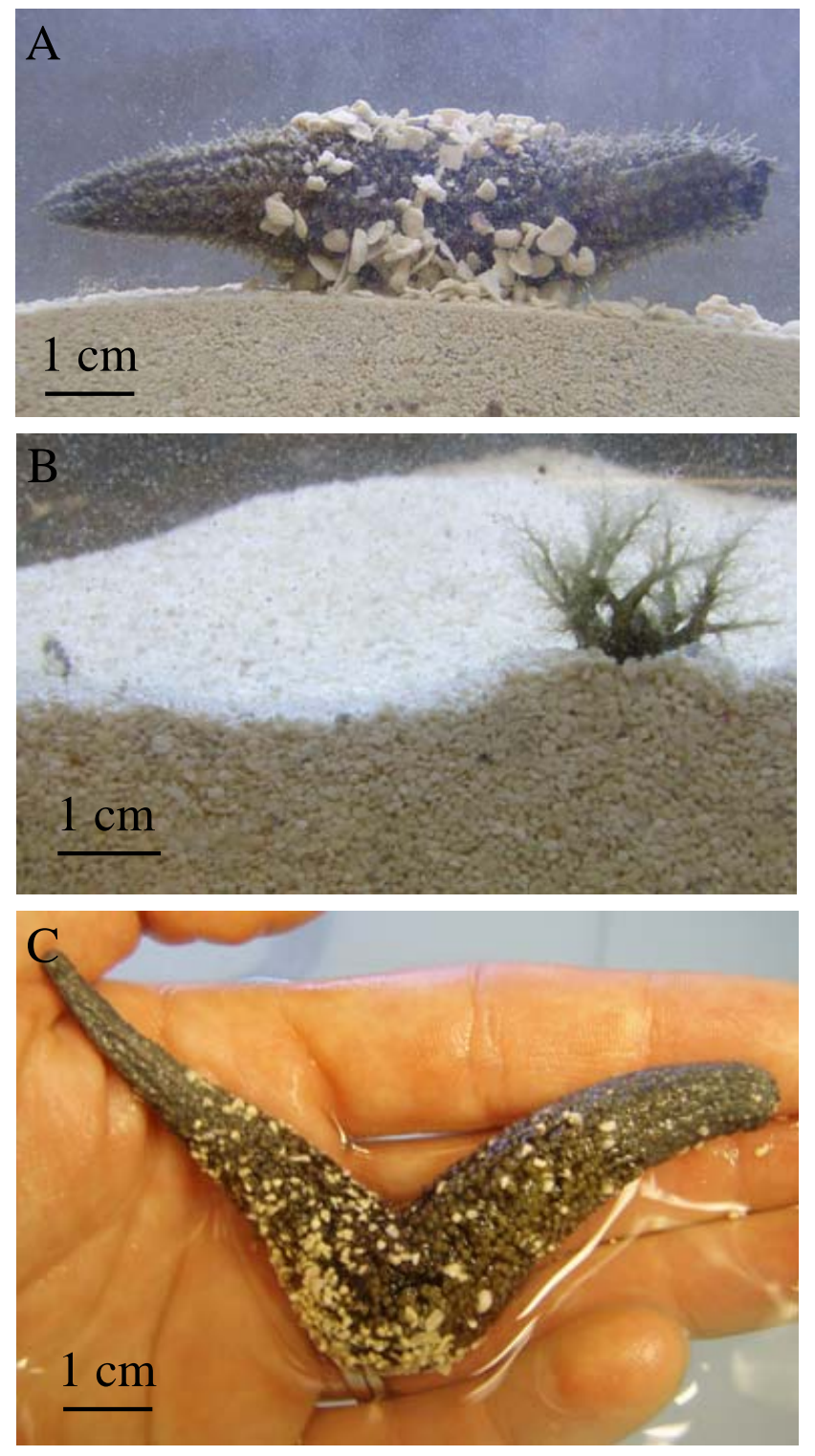

Fig. (3). A) Thonella gemmata with a contracted, rigid body and narrow anterior and posterior ends. B) Buried T. gemmata with the anterior tentacle crown and posterior anus projecting above the sand. C) Specimen of $T$. gemmata after removal from its burrow. The specimen was rigid and retained the shape it had while in the burrow.

to acclimate to the conditions in the tanks before experimental tests were performed.

The three specimens in tanks 2 and 3 were exposed to changing environmental conditions. Three experimental environmental variables were studied: 1) sediment grain size; 2) salinity; and 3) temperature (Table 1). The environmental variables were applied one at a time while the other two variables were maintained at normal conditions. The specimens were exposed to a particular altered variable for 1-2 days in order to observe complete burrowing.

The first environmental variable applied was sediment grain size which included fine- $(0.1-1.0 \mathrm{~mm})$, medium- $(0.5-$ $1.5 \mathrm{~mm})$, and coarse-grained $(1.0-2.0 \mathrm{~mm})$ carbonate sand
Table 1. Experimental Environmental Parameters Applied to Specimens of T. gemmata in Tanks 2 and 3

\begin{tabular}{|c|c|c|c|}
\hline & Sediment Size & Temperature & Salinity \\
\hline \hline \multicolumn{2}{|c|}{ A. Stable Conditions } \\
\hline & $0.5-1.5 \mathrm{~mm}$ & $20-22^{\circ} \mathrm{C}$ & $29.2-31.9 \%$ \\
\hline B. Sediment Size \\
\hline Trial 1 & $0.1-1.0 \mathrm{~mm}$ & $20-22^{\circ} \mathrm{C}$ & $29.2-31.9 \%$ \\
\hline Trial 2 & $0.5-1.5 \mathrm{~mm}$ & $20-22^{\circ} \mathrm{C}$ & $29.2-31.9 \%$ \\
\hline Trial 3 & $1.0-2.0 \mathrm{~mm}$ & $20-22^{\circ} \mathrm{C}$ & $29.2-31.9 \%$ \\
\hline Trial 4 & Layered $0.5-1.5 \mathrm{and}$ & $20-22^{\circ} \mathrm{C}$ & $29.2-31.9 \%$ \\
\hline C. Salinity & $1.0-2.0 \mathrm{~mm}$ & $20-22^{\circ} \mathrm{C}$ & $40 \%$ \\
\hline Trial 1 & $0.5-1.5 \mathrm{~mm}$ & $20-22^{\circ} \mathrm{C}$ & $29.2-31.9 \%$ \\
\hline Trial 2 & $0.5-1.5 \mathrm{~mm}$ & $20-22^{\circ} \mathrm{C}$ & $20 \%$ \\
\hline Trial 3 & $0.5-1.5 \mathrm{~mm}$ & \multicolumn{3}{|l}{} \\
\hline D. Temperature & $0.5-1.5 \mathrm{~mm}$ & $29.2-31.9 \%$ \\
\hline Trial 1 & & $29.2-31.9 \%$ \\
\hline Trial 2 & $0.5 \mathrm{~mm}$ & & \\
\hline
\end{tabular}

(Table 1). These trials were performed using 9.5 L aquaria in which two glass plates were inserted spaced approximately $1.5 \mathrm{~cm}$ apart. The glass plates were used to laterally confine the specimen in order to clearly observe and document burrowing behavior in cross-section throughout each trial. Approximately $10-12 \mathrm{~cm}$ of sand was then placed between the glass plates. The small aquaria were placed in the $212 \mathrm{~L}$ aquaria during the experiments in order to maintain the proper salinity and temperature levels. The specimens were then placed between the glass plates and observed while they

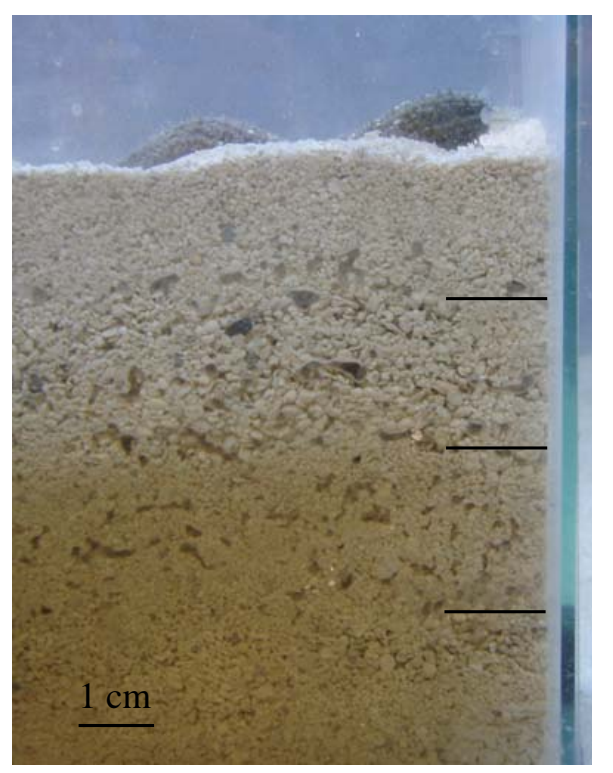

Fig. (4). A specimen of T. gemmata initially burrowing into layered medium- and coarse-grained carbonate sand. Each layer is approximately $1.5 \mathrm{~cm}$ thick. 
burrowed into the substrate. This process was duplicated for each of the three sediment grain sizes. A fourth trial was also run using $1.5 \mathrm{~cm}$ thick alternating layers of medium- and coarse-grained (Table 1, Fig. 4). This trail was conducted to observe how well the specimen disrupted and mixed the sediment as it penetrated the substrate as well as to determine if burrowing habits changed vertically as the specimen encountered different grain sizes.

To test the effect of changing salinity, a stand-alone $9.5 \mathrm{~L}$ aquarium was used containing $8-10 \mathrm{~cm}$ of $0.5-1.5 \mathrm{~mm}$ carbonate sand, salt water, and a filter to maintain water circulation. The salinity of the water was varied from normal marine (29.2-31.9\%), brackish (20\%), and hypersaline (40\%) (Table 1). Before being placed into the test aquarium, the specimen was set into a small container filled with water from its holding tank mixed with either the $40 \%$ or $20 \%$ water to acclimate for approximately 30 minutes. The single specimen was then placed in the tank to determine if the change in salinity affected whether the animal burrowed in the altered environment and, if so, if the altered salinity affected the efficiency of burrowing.

To test the effect of water temperature on burrowing behavior, the temperature in Tank \#3 containing two specimens in medium-grained sand was raised progressively from $21^{\circ} \mathrm{C}$ to $32^{\circ} \mathrm{C}$. The temperature was increased in $2^{\circ}$ increments over the course of approximately 5 hours. The maximum temperature of $32^{\circ} \mathrm{C}$ was maintained for an additional 5 hours. Burrowing habits were observed throughout the trial.

\section{RESULTS}

\section{Altering Sediment Grain Size}

In Trial 1, the specimens were placed in an aquarium filled with sediment composed of grain sizes ranging from 0.1-1.0 $\mathrm{mm}$. When the specimen was placed between the glass plates, it remained on the surface in a rigid posture for 5-10 minutes (Fig. 5A). The specimen retained sand grains

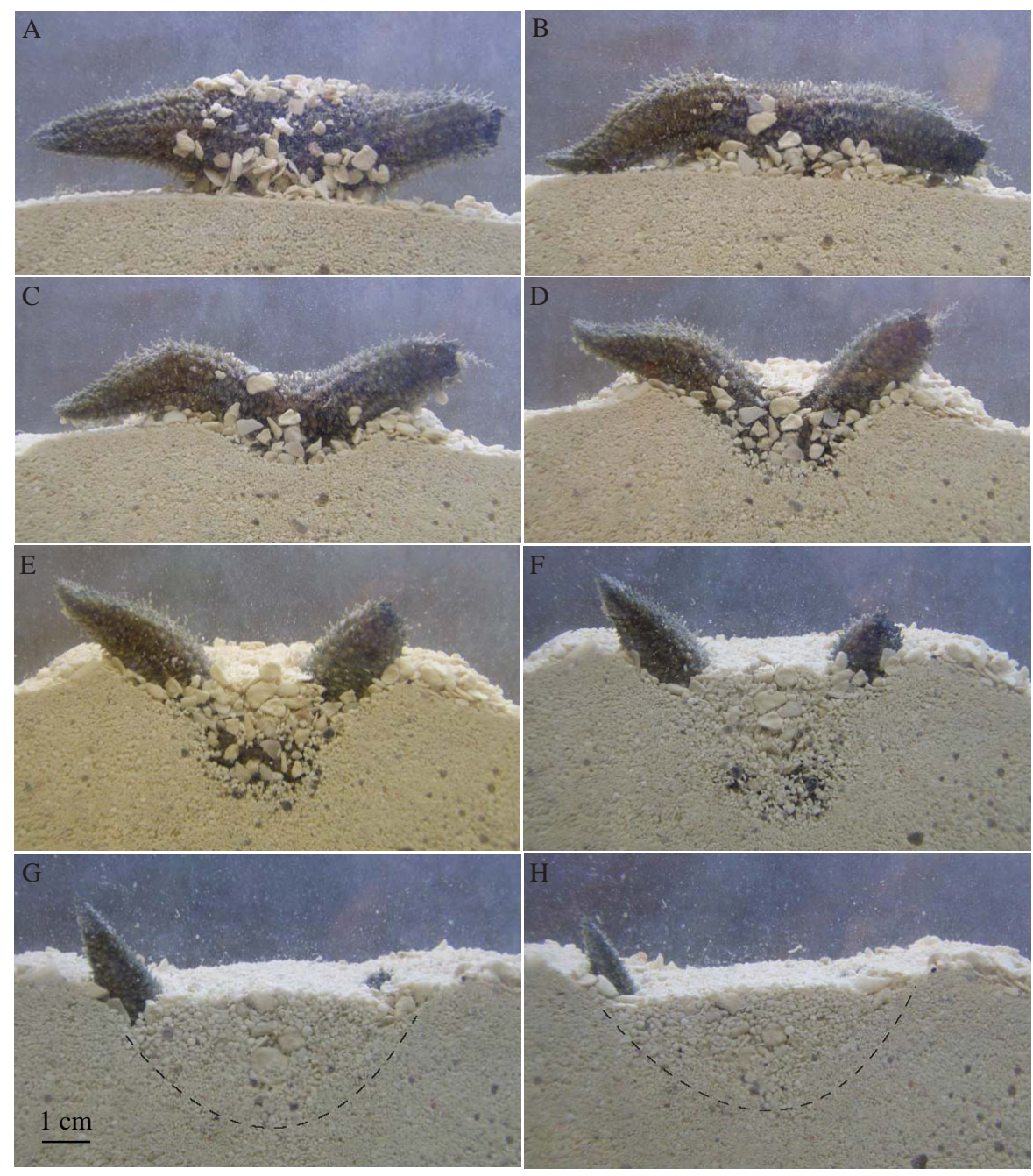

Fig. (5). Complete burrowing sequence of T. gemmata in fine-grained carbonate sand. A) The specimen remains rigid when placed on the sediment surface. B) Once relaxed, the specimen begins muscular contractions and starts to penetrate the sediment. C) Podia aid in burrowing by carrying sand grains away from the growing depression beneath the center of the animal. D) The specimen continues to contract its body into a U shape. E) Sand grains fill the depression forming above the center of the animal. F) Podia attach to grains of sand and form a cover around the animal's body. G) Once burrowing is complete, the anterior and posterior ends of the animal are left in contact with the surface. The dashed line outlines the base of the U-shaped burrow. H) Over time the holothurians body may relax and form a broader U shape. 
from its holding tank due to contraction of the body wall and podia. Once relaxed, the specimen moved along the surface and investigated the area for approximately 20 minutes before burrowing began (Fig. 5B). Once burrowing was initiated, the specimen pushed itself easily into the sand taking approximately 3 hours for the specimen to completely move below the sediment-water interface.

To begin burrowing, T. gemmata used the middle portion of its body to penetrate the sand creating a small depression (Fig. 5B). Muscular contractions within the body wall played a large role in this phase of downward movement. The podia were then used to carry sand grains away from the depression (Fig. 5C-D). The specimen continued to penetrate the sediment while acquiring a more pronounced U-shape by contracting the muscles in the body wall and using its podia to transport sediment grains (Fig. 5D-E). As the specimen burrowed deeper into the substrate, the surrounding sand collapsed into the depression formed in the middle of the "U" (Fig. 5E-F). While burrowing, the specimen also attached grains of sand to its body surface using the podia (Fig. 5F). As a result, the specimen within its burrow was not completely visible in the side of the glass plates. During the final stages of burrowing, the posterior end of the specimen remained in contact with the water column and the anterior end was slightly exposed at the sediment-water interface (Fig. 5G-H). The specimen later extended its tentacles to feed. The final depth of this burrow was approximately $4 \mathrm{~cm}$. When the specimen was disturbed, it quickly burrowed deeper into the substrate to a depth of approximately $8-10 \mathrm{~cm}$, often reaching the bottom of the aquarium. At the end of the experiment, the specimen was still buried deeply so it was removed from the substrate. When excavated, the holothurian retained the body shape it had maintained in its deep burrow (Fig. 3C).

In Trial 2, the specimens were placed on a layer of $0.5-$ $1.5 \mathrm{~mm}$ carbonate sand. The specimens burrowed easily and in similar fashion and time frame to the previous trial performed using the fine-grained sand (Fig. 6). Once the specimens had fully burrowed, they were disturbed using a glass rod. Each of the specimens was able to quickly burrow up to $10 \mathrm{~cm}$ into the sediment for protection.

In Trial 3, the specimens were placed on a layer of 1.0$2.0 \mathrm{~mm}$ carbonate sand. The specimens experienced difficulty burrowing compared to the efficient burrowing that took place within the fine- and medium-grained sand.
Complete burrowing of the animal took approximately two hours longer than in finer-grained sand. Once burrowed in the coarse sand, the holothurian's body was in the shape of an asymmetrical "U" (Fig. 7A). Later the specimen was able to further adjust its body in the substrate and form a more uniform U-shape (Fig. 7B). When disturbed at the surface, the specimen moved its entire body below the sedimentwater interface, but did not burrow any deeper into the sand as the specimens did within the fine- and medium-grained sand.

Trial 5 involved the use of the alternating layers of medium- and coarse-grained carbonate sand (Fig. 4). When placed upon these substrates, the specimens efficiently burrowed into the top layer of medium-grained sand and transported some of the medium-grained sand into the coarse-grained layer below (Fig. 7C-D). The specimens did not burrow through the coarse-grained sand layer. When disturbed at the surface, the specimens only contracted into their burrows but did not increase their burrow depth.

\section{Altering Salinity}

When placed in a 2.5-gallon aquarium filled with water with a salinity of $40 \%$ for Trial 1 , the specimen explored the substrate with its tentacles for approximately 20 minutes. The specimen then moved to the side wall of the tank and began to burrow in a similar fashion to the burrowing that took place in the fine- and medium-grained sand. The specimen burrowed with efficiency and did not appear to be affected by the increased salinity.

When exposed to water with a salinity of $20 \%$ in Trial 2, the specimen of $T$. gemmata appeared to be detrimentally affected by the lowered salinity. The specimen did not move from the place in which it was initially set within the aquarium. It instead investigated the sand in its immediate area with its tentacles for approximately 15 minutes before withdrawing. The posterior portion of the specimen's body then began to curl. It was at that point that the specimen was withdrawn from the small tank, acclimated to water of a higher salinity in a small container, and then returned to its holding tank with normal marine salinity.

\section{Altering Water Temperature}

Raising the temperature to $32^{\circ} \mathrm{C}$ did not have any observed effect on the burrowing behavior $T$. gemmata. The
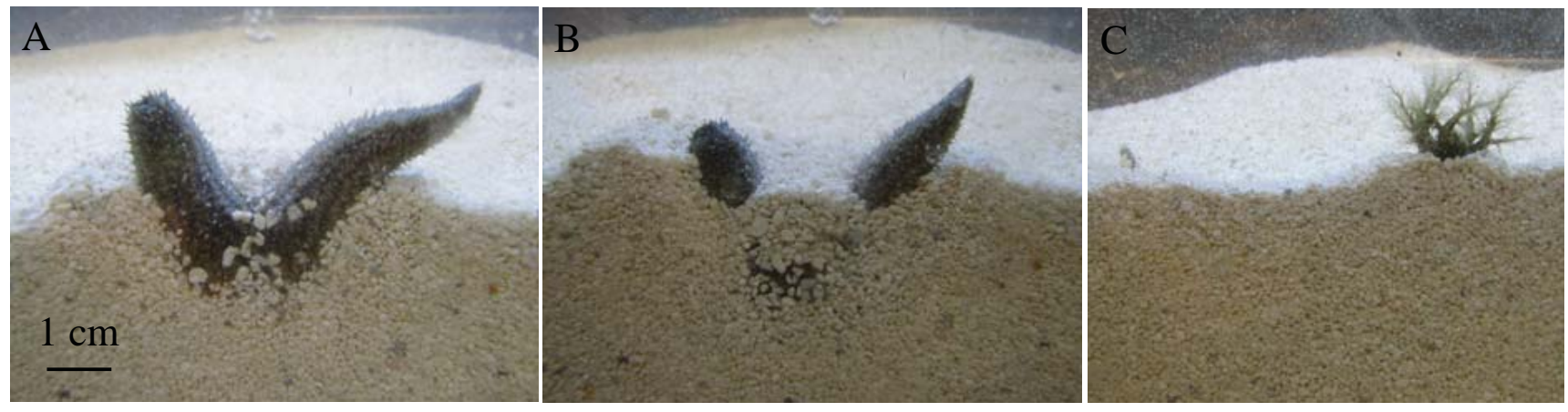

Fig. (6). Complete burrow sequence in medium-grained carbonate sand. A) Initial penetration of the sediment in a U shape. B) Passive fill of the depression formed above the center of the animal. C) Final position beneath the sediment surface. 

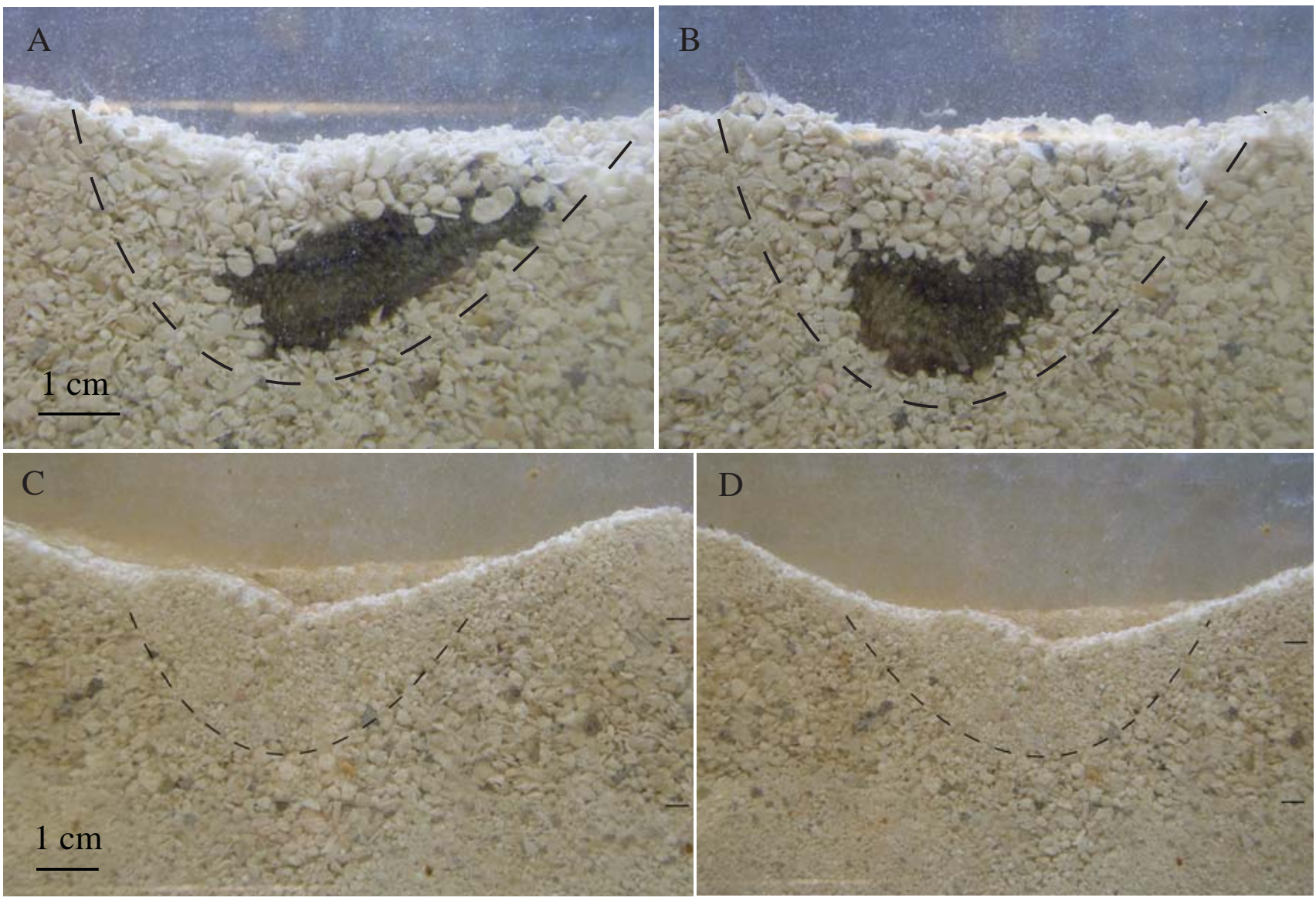

Fig. (7). Specimen burrowed into coarse-grained (A-B) or layered (C-D) carbonate sand. A) The initial shape of the burrow formed in coarse-grained sand is a lop-sided U. B) Later, the specimen's body contracted into a more symmetrical U shape. C) When encountering interbedded medium- and coarse-grained sand, the holothurian penetrated the medium-grained surface layer but did not fully penetrate the underlying coarse-grained layer. Medium-grained sand is transported downward by the burrowing animal. D) When disturbed at the surface, the specimen pushes downward through the coarse-grained layer. The dashed line outlines the burrow.

specimens burrowed in the same manner and time as they did in $21^{\circ} \mathrm{C}$ water.

\section{DISCUSSION}

\section{Ichnotaxonomy}

The holothurian Thyonella gemmata produced distinct biogenic structures in each of the experimental trials with the exception of the reduced salinity experiment. In each of the trials, as the specimens burrowed into the sediment, the overlying sand filled a U-shaped void between the shafts of the burrow creating a disrupted fill (Fig. 5D-F). An open burrow consisting of two irregular, subvertical shafts connected by a short tunnel at the base of the structure was maintained by the intrusion of the animal's body into the sediment. The resulting structure was an irregular U-shaped burrow with a zone of layered to homogenized sediment in between the paired shafts.

Arenicolites and Diplocraterion are two common Ushaped burrows typically found in shallow marine deposits. Arenicolites and Diplocraterion are both characterized by a vertically oriented pair of shafts connected by a tunnel at the base of the structure. Arenicolites is traditionally described as an open U-shaped burrow with no spreite between the burrow shafts [11]. In the modern this type of burrow is often produced in low energy environments, such as the lower shoreface or tidal flats, and serves as the dwelling burrow for suspension-feeding organisms [12]. Diplocraterion is described as a U-shaped burrow with spreite between or below the burrow shafts [11]. The spreite are produced as the organism adjusts its position within the sediment in response to sediment deposition or erosion [9, 12]. In the modern this type of burrow is typically produced by suspension-feeding organisms inhabiting higher energy environments, such as the middle shoreface or high energy tidal flats [12].

The T. gemmata burrows do not possess distinct spreite as defined in Diplocraterion, and are therefore more similar to Arenicolites. From the observations of T. gemmata behavior, however, it is possible that spreite could be produced during long-term occupation of a burrow. These spreite would likely extend from the base of the burrow resulting from the upward movement of the holothurian within the sediment as a result of sediment accumulation. These would be similar to the spreite produced by the holothurian Thyone briareus as it moves its U-shaped body upward in the substrate in response to gradual sediment deposition $[5,13]$. The U-shaped shafts of both Arenicolites and Diplocraterion 
typically possess sharp wall boundaries and passive fill which indicates that the burrows were kept open and free of sediment by the inhabiting organism [12]. Thyonella gemmata, however, did not leave open shafts when the animals evacuated their burrows. The observations in the experiments also indicate that $T$. gemmata does not reinforce its burrow walls to maintain an open burrow; the presence of the holothurian itself maintains the sediment-free space in the subsurface. While it is possible that the sediment of the burrow walls may become indurated and self-supporting after long-term use, this result was not observed in the laboratory. For these reasons, the U-shaped burrow produced by $T$. gemmata appears to be unique and cannot be assigned to either ichnogenus.

Since the burrows produced by $T$. gemmata cannot be assigned to an established ichnogenus, it is necessary to examine the burrow structures produced by these modern organisms in order to determine which architectural properties of the burrow may be recognized in the fossil record. The specimens used in this study produced the same general burrow morphology every time they burrowed. The burrow morphology consists of a wide, U-shaped concentration of disrupted sediment and spreite may occur below the burrow if the organism moved vertically in the substrate. While $T$. gemmata is in its burrow, the open burrow takes the shape of the body of the holothurian. A potential open burrow left behind when the holothurian leaves the sediment would have a total length of approximately $8 \mathrm{~cm}$. The diameter of the burrow would be wider at the base of the "U" and would decrease upward along the limbs. The total width and depth of the burrow would vary depending on the individual organism's size, position within the substrate, and substrate consistency.

\section{Other Examples from the Modern and Fossil Record}

Despite the common occurrence of burrowing holothurians in modern shallow to deep marine environments, there has been little documentation on the subsurface biogenic structures produced by these animals in either the modern or the ancient. The extant holothurians Thyone briareus [5, 13-17], Holothuria scabra [4], and Protankyra bidentata [18] are three exceptions. Pearse [5] conducted various experiments with $T$. briareus including some designed to observe the animals burrowing methods. Thyone briareus was found to burrow in a similar manner to $T$. gemmata, wedging its way down into the sediment through muscular contractions in a rough U-configuration with the two ends of the body turned upward. Despite the description of the burrowing methods, however, Pearse [5] did not describe the structures produced by $T$. briareus in the sediment. Howard [13] conducted experiments with several marine animals including Thyone $\mathrm{sp}$ for the purpose of investigating the potential application of X-radiography to the study of bioturbation. The experiments were designed to test the reaction of the organisms to changes in environment; for the holothurnians sediment layers were gradually added to determine the types of escape patterns produced by Thyone. The X-radiographs revealed that cup-in-cup structures were produced as the holothurians gradually moved upward in response to sediment aggradation [13]. Field observations of Thyone have shown that they produce irregular U-shaped burrows similar to those of $T$. gemmata in intertidal settings although these have not been described in detail $[16,17]$. Laboratory experiments with $H$. scabra indicated that this species burrowed in response to daylight and decreasing salinity, however, neither the burrowing method nor the burrows were described in this study [4]. Field observations on tidal flats have shown that $P$. bidentata produces L- to J- shaped burrows with a single surface opening and some broadly U-shaped burrows with a single opening [18]. The burrows are typically $5-10 \mathrm{~cm}$ deep and occur in muddy sediment. These holothurians are deposit feeders and appear to obtain most of their sediment for ingestion in the course of burrow excavation [18]. Further feeding takes place at the sediment surface near the burrow opening [18]. This difference in behavior accounts for the difference in burrow morphology between P. bidentata and T. gemmata.

The ichnospecies Artichnus pholeoides from the Middle to Late Eocene Hieroglyphic Beds of the Polish Carpathians was interpreted as the dwelling burrow of holothurians [19]. This ichnofossil is described as a wide, J-shaped passively filled burrow surrounded by thickly laminated, mostly retrusive spreite best developed in the lower part of the structure [19]. The structure is interpreted as having one opening for the tentacle crown to pass through during feeding. With the absence of a second opening, fecal material would be deposited around and beneath the holothurian producing a laminated halo, or spreite, around the burrow [19]. The single opening would suggest a different style of burrowing than T. gemmata. The holothurian Synapta has been found to burrow 'head first' using its tentacles to move sediment particles and intrude its body into the substrate [20]. This process of burrow construction would likely produce an elongate, cylindrical structure similar to A. pholeoides. The burrows produced by $P$. bidentata are also morphologically similar to $A$. pholeoides although they do not possess a wide basal chamber [18].

Ichnofossils with morphological characteristics similar to the burrows produced by $T$. gemmata in the laboratory have been found in fossiliferous wackestone and packstone of the Ames Member of the Glenshaw Formation (Kasimovian). The ichnofossil is a U-shaped structure with a fill of poorly sorted bioclasts and spar (Fig. 8). The diameter of the

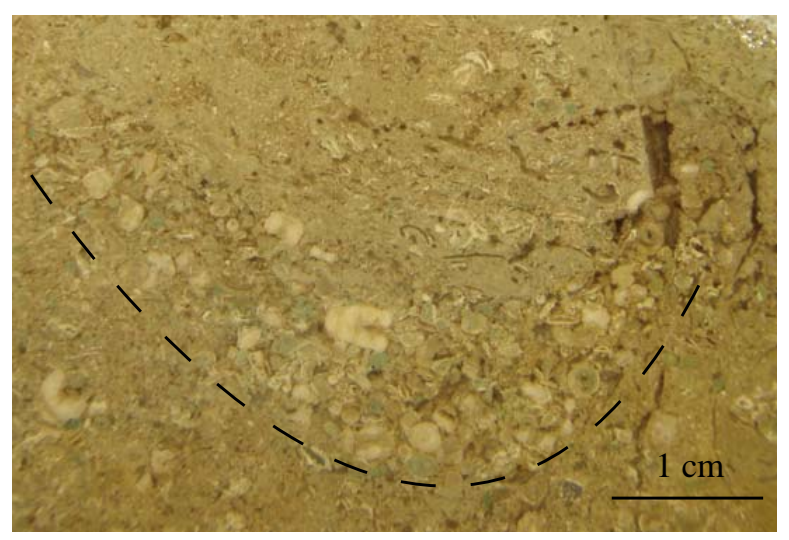

Fig (8). A U-shaped ichnofossil from the Pennsylvanian Ames Member of the Glenshaw Formation (Kasimovian), southeast Ohio. The ichnofossil resembles the burrow morphology of Thyonella gemmata. 
structure is greatest along the base and tapers upward along the two upturned shafts. The upper margin of the ichnofossil is characterized by a zone of disruption that is distinct from the surrounding sedimentary texture. An animal, likely a holothurian, burrowing using a method similar to $T$. gemmata could have created the disrupted fill. When the animal reached its required position within the sediment its body occupied open burrow. When the organism evacuated the burrow or possibly died within the burrow, the resulting void was passively filled with coarse fossil debris and later calcite spar crystallized in the remaining pore spaces.

\section{Paleoenvironmental and Paleoecological Significance}

The experiments described in this paper demonstrate that holothurians can produce biogenic structures that can be distinguished from the surrounding primary sedimentary fabric. Since holothurians have a long-ranging, but extremely incomplete fossil record, the identification of their burrows provides an additional means of interpreting their true evolutionary and biogeographic history.

Once an ichnofossil resembling that produced by $T$. gemmata is recognized in the fossil record, interpretations regarding the depositional environment can also be made. The burrowing activities and resulting morphologies of $T$. gemmata reflect habitation in a subtropical, shallow, nearshore environment. The specimens did not react to an increase in water temperature to $32^{\circ} \mathrm{C}$. This is consistent with dwelling in intertidal environments in equatorial regions where intense heat from the sun can increase water temperatures to over $32^{\circ} \mathrm{C}$ during low tides [6]. The specimens also did not react to an increase in salinity to $40 \%$, which can be produced by increased ambient temperature resulting in the excess evaporation of sea water in intertidal environments [6]. There was an effect on the specimen placed in water with a salinity of $20 \%$ indicating that in the natural environment, T. gemmata would not inhabit an area with freshwater input. Altering substrate consistency had the greatest effect on burrowing activities and the burrow morphology. The test specimens were able to easily burrow in fine- and medium-grained carbonate sand, but had difficulty burrowing in coarse-grained sand. This suggests that the burrowing method of $T$. gemmata restricts them to finer grained sediments. In marine settings finer-grained sediments are typically deposited in the nearshore, low energy environments, such as in bays or on tidal flats [18, $21,22]$.

Given the know behaviors and environmental preferences of extant holothurians, the recognition of a burrow that resembles that of $T$. gemmata in the fossil record allows for the interpretation of: 1) the presence of a holothurian or holothurian-like organism; 2) the presence of suspended nutrients in the water column to support at least limited suspension-feeding; 3) a salinity level that does not decrease greatly from normal, but may increase from normal; 4) a low energy, shallow water paleoenvironment where the substrate is composed mainly of fine- to medium-grained sediment; and 5) the sediment-water interface at or near the top of the burrow. Additionally, the preservation of a delicate burrow produced near the sediment-water interface indicates that there was not an abundance of other burrowing organisms in the paleoenvironment. Generally, shallow tier burrows are obliterated by deeper tier burrows as sediment accumulates on the sea floor [9]. The presence of a burrow like that of $T$. gemmata may indicate that the environmental conditions, such as oxygen content or nutrient availability within the sediment, were not adequate to support shallow-tier, depositfeeding organisms.

\section{CONCLUSIONS}

Thyonella gemmata produces a simple biogenic structure that may be recognized in the fossil record as a U-shaped zone of disrupted sediment that is unlike the fabric of the surrounding sediment. The burrows are shallow and reflect suspension-feeding behavior. In this experiment, the burrowing behaviors and resulting morphologies of $T$. gemmata were observed as specimens were exposed to varying sediment grain sizes, salinity levels, and increased temperature. These experimental parameters reflected conditions that the specimens may have been exposed to in their natural environment.

To burrow, Thyonella gemmata contracted the muscles in its body wall and used numerous podia to penetrate the sediment while maintaining its body in the shape of a "U." When fully burrowed, the anterior and posterior of the holothurian was slightly exposed to the water for respiration, feeding, and excretion. The burrow morphology produced by T. gemmata was a wide, U-shape. The burrow was thicker along the bend of the "U" than the limbs. When exposed to the environmental parameters of increased temperature and higher than normal salinity, burrow morphology did not appear to change. Salinity levels below normal marine conditions, however, inhibited burrowing behaviors. Altering the sediment grain size had the greatest effect on burrow morphology, in particularly coarse-grained sand which the specimen had difficulty burrowing into effectively. In coarse-grained sand, the length of time the specimen required to completely burrow beneath the surface was substantially longer compared to the fine- and medium-grained sands, the final burrows tended to be shallower, and the resulting burrow form was an asymmetrical "U."

It is necessary to study the burrow morphologies produced by modern holothurians in order to refine their occurrence in the fossil record, since their soft-anatomy and fragile sclerites are not readily preserved. The data collected in these experiments can be applied to the fossil record to better interpret potential holothurian tracemakers as well as to aid in the interpretation of the paleoenvironmental conditions of substrate, temperature, and salinity. The burrow morphologies produced by $T$. gemmata in this study reflect habitation in shallow water, subtropical environments where environmental conditions may change on a daily or seasonal basis. The $T$. gemmata burrow morphology data as well as information regarding the sedimentology, stratigraphy, and the body fossils found in strata provide a more complete understanding of nearshore paleoenvironmental conditions.

\section{CONFLICT OF INTEREST}

None declared. 


\section{ACKNOWLEDGEMENTS}

We would like to thank Drs. Gregory C. Nadon and Gregory Springer for their comments on an earlier draft of this manuscript. We would also like to thank two anonymous reviewers for their comments and suggestions that helped improve this manuscript. This research was partially supported by an Ohio University Geological Sciences Alumni Grant and a Geological Society of America Grant-In-Aid.

\section{REFERENCES}

[1] Bakus GJ. The biology and ecology of tropical holothurians. In: Jones OA, Endean R, Eds. Biology and Geology of Coral Reefs. New York, Academic Press 1973; 2: 325-67.

[2] Ruppert, EE, Barnes, R.D. Invertebrate Zoology. Orlando: Harcourt 1996.

[3] Scholle PA, Ulmer-Scholle DS. A color guide to the petrography of carbonate rocks: grains, textures, porosity, diagenesis. Mem Am Assoc Petrol Geol Memoir Series, 2003; Vol. 77.

[4] Mercier A, Battaglene SC, Hamel, JF. Daily burrowing cycle and feeding activity of juvenile sea cucumbers Holothuria scabra in response to environmental factors. J Exp Biol Ecol 1996; 239: 12556.

[5] Pearse AS. Observations on the behavior of the holothurian, Thyone briareus (Leseur). Biol Bull Mar Biol Lab Woods Hole 1908; $15: 259-88$

[6] Schäfer W. Ecology and palaeoecology of marine environments. Edinburgh: Oliver \& Boyd 1972.

[7] Frizzell DL, Exline H, Pawson DL. Holothurians. In: Moore RC, Ed. Treatise on invertebrate paleontology, part U, echinodermata 3(2). Lawrence: Geological Society of America and University of Kansas Press 1966; pp. 641-72.

[8] Rhoads DC. The paleoecological and environmental significance of trace fossils. In: Frey RW, Ed. The study of Trace Fossils: A synthesis of principals, problems, and procedures in ichnology. New York: Springer-Verlag 1975; pp. 147-60.

[9] Bromley RG. Trace fossils: biology, taphonomy, and applications. $2^{\text {nd }}$ ed. London: Chapman and Hall; 1996.

[10] Steinmeier RC, Parkhurst LJ. Oxygen and carbon monoxide equilibriums and the kinetics of oxygen binding by the cooperative dimeric hemoglobin of Thyonella gemmata. Biochemistry 1979; 18: 4645-51.

[11] Häntzschel W. Trace fossils and problematica. In: Teichert C, Ed. treatise on invertebrate paleontology part W (Supplement 1). Lawrence: Geological Society of America and University of Kansas Press 1975; 2-269.

[12] Pemberton SG, Spila M, Pulham AJ, et al. Ichnology and sedimentology of shallow to marginal marine systems: ben nevis and avalon reservoirs, jeanne d'arc basin. Newfoundland: Geological Association of Canada 2001.

[13] Howard JD. X-ray radiography for examination of burrowing in sediments by marine invertebrate organisms. Sedimentology 1968 11: $249-58$

[14] Frey RW. Environmental significance of recent marine lebensspuren near beaufort, North Carolina. J Paleontol 1970; 44: 507-19.

[15] Frey RW, Howard JD. Georgia coastal region, Sapelo Island, USA: sedimentology and biology. VI. Radiographic study of sedimentary structures made by beach and offshore animals in aquaria. Senckenb Marit 1972; 4: 169-82.

[16] Gingras MK, Pemberton SG, Dashtgard S, Dafoe L. How fast do marine invertebrates burrow? Palaeogeogr Palaeoclimatol Palaeoecol 2008; 270: 280-6.

[17] Gingras MK, Dashtgard S, MacEachern, JA, Pemberton SG. Biology of shallow marine ichnology: a modern perspective. Aquat Biol 2008; 2: 255-68.

[18] Frey RW, Howard JD, Hong JS. Prevalent lebensspuren on a modern macrotidal flat, Inchon, Korea: ethological and environmental significance. Palaios 1987; 2: 517-93.

[19] Zhang G, Uchman A, Chonyń R, Bromley RG. Trace fossil Artichnus pholeoides igen. nov. isp. nov. in Eocene turbitides, Polish Carapathians: possible ascription to holothurians. Acta Geologica Polonica 2008; 58: 75-86.

[20] Clark HL. The synaptas of the New England coast. United states commission of fish and fisheries. Contributions from the Biological Laboratory at Woods Hole 1899; 426: 21-31.

[21] Potter PE, Maynard JB, Depetris PJ. Mud and Mudstones. Berlin: Springer-Verlag 2005

[22] Frey RW, Howard JD, Han SJ, Park BK. Sediments and sedimentary sequences on a modern macrotidal flat, Inchon, Korea. J Sediment Petrol 1989; 59: 28-44. 